\title{
Jardins de infância públicos estaduais na cidade de Campos dos Goytacazes na primeira metade do século $\mathbf{X X}$
}

\author{
Public state kindergartens in the city of Campos dos \\ Goytacazes on first half century 20
}

\author{
Vinicius Monção \\ Orcid: http://orcid.org/0000-0002-3353-1655 \\ Universidade Estadual do Norte Fluminense Darcy Ribeiro, Rio de Janeiro, Brasil, \\ vinimoncaodois@gmail.com
}

Silvia Alicia Martínez

Orcid: http://orcid.org/0000-0001-9612-6924

Universidade Estadual do Norte Fluminense Darcy Ribeiro, Rio de Janeiro, Brasil, silvia-martinez@hotmail.com

Received on 04/12/2020 - Approved on 14/12/2020

\section{Resumo}

O artigo tem como objetivo mapear os jardins de infância públicos, criados e mantidos pelo governo estadual entre as décadas de 1920 e 1940, na cidade de Campos dos Goytacazes, localizada na região norte do estado do Rio de Janeiro. Foram analisados os mapas de frequência escolar e dos adjuntos existentes no Fundo Departamento de Educação do Arquivo Público do Estado do Rio de Janeiro. As análises se apoiaram nas proposições oriundas da História Social da Educação. Tal perspectiva está interessada em um possível afastamento de uma postura paternalista para responder sobre a implementação da pré-escola pública. Como resultado, percebe-se que a criação dos jardins de infância estava relacionada com a renovação da instrução pública e especialização no magistério público.

Palavras-chave: Jardim de infância. História da Educação. História da educação infantil. História da educação fluminense. Campos dos Goytacazes. 


\begin{abstract}
The aims of article are to map the public kindergartens, created and maintained by the state government between 1920s and 1940s, in the city of Campos dos Goytacazes, localized on northern region of the state of Rio de Janeiro. We analyzed the "mapas de frequência escolar e dos adjuntos" that belong to of "Fundo Departamento de Educação do Arquivo Público do Estado do Rio de Janeiro". The analysis was supported to start Social History of Education. We proposed a look beyond a paternalistic perspective to ask about the implementation of public preschool. As result, we can see that kindergarten creation was related with a renovation movement of public instruction and the public teaching specialization.
\end{abstract}

Keywords: Kindergarten. History of Education. History of childhood education. History of education in Rio de Janeiro. Campos dos Goytacazes.

\title{
Introdução'
}

Investir sobre a história da educação fluminense nas primeiras décadas republicanas não é uma tarefa fácil tendo-se em vista alguns fatores como o número enxuto de pesquisas sobre a temática e a complexidade político-social do período. Neste cenário destacamos bons exemplos de contribuições para aquecer a temática entre os historiadores, ampliando, inclusive, os enfoques temáticos, como os Encontros de História da Educação do Estado do Rio de Janeiro, realizados em 2007, 2010 e 2013; as publicações de Vasconcelos e Faria (2010) e Mendonça e Vasconcelos (2013); e mais recentemente, o dossiê da Revista Contemporânea de Educação publicado em 2019.²

Ao que compete à temática da expansão da malha da escola pública no território fluminense, as mensagens dos Presidentes do Estado do Rio de Janeiro, a partir de 1893, apresentam constantemente um discurso voltado para a renovação pedagógica no Estado como a necessidade de criação de escolas a partir do modelo dos grupos escolares, aos moldes daquele implementado pelo governo paulista; o estabelecimento de regras para a compra de prédios escolares, a fim de atender à crescente demanda da população por escolarização, entre outros (Schueler, 2010). Contudo, assim como já indicado por Nagle (1974), e corroborado por Schueler e Gondra (2008), Schueler e Magaldi (2009) e Schueler (2010), as ações governamentais efetuadas nas primeiras décadas republicanas buscavam construir um novo discurso a partir do estabelecimento de uma ideia de ruptura com o governo imperial, ao adotarem uma agenda de expansão e modernização pedagógica para o Estado. Contudo, é importante apontar que as discussões sobre a modernização pedagógica já estavam em efervescência desde a segunda metade do século XIX.

As ações governamentais voltadas para a expansão da malha escolar pública fluminense intensificaram-se entre as décadas de 1910 e 1920 (Rodrigues, 2014). O presidente do Estado Raul Veiga (1918-1922) esteve empenhando em "restaurar a Idade de Ouro e a pujança econômica, cultural e política da Velha Província, e a política de construção de grupos escolares tornava-se o leitmotiv da ação governamental" (Schueler, 2010, p. 543. Grifos no original).

Foi a partir da 1925 que a educação pré-escolar foi inserida na estrutura da instrução pública, pelo decreto n. 2.105, que regulamentou a instrução primária do estado do Rio de Janeiro. Para além do ensino primário elementar, o artigo $6^{\underline{a}}$ do 
Decreto passou a admitir a criação de escolas maternais e jardins de infância, via ônus dos cofres do estado fluminense (Estado do Rio de Janeiro, 1925). No entanto, embora saibamos que a expansão da escola primária se deu nesse período, pouca coisa sabemos sobre a inserção, oferta e expansão da escola pré-primária, tendo em vista que a temática não tem sido explorada pelo campo da história da educação. Desta forma, o presente artigo busca contribuir com as discussões sobre a implementação de instituições pré-escolares públicas criadas e mantidas pelo governo do estado do Rio de Janeiro na primeira metade do século XX.

Dentre as categorias educativas criadas para o atendimento escolar de crianças menores de sete anos pela estrutura pública, foram criadas escolas maternais e jardins de infância. Embora ambas estivessem voltadas para o atendimento pré-escolar, cada modalidade possuía uma estrutura e função específica.

As escolas maternais eram destinadas à "guarda e educação de crianças pobres de três a seis anos de idade", que seriam criadas preferencialmente, "nas proximidades dos estabelecimentos industriais". No ato da matrícula, os pais deveriam comprovar que eram pobres, operários ou domésticos; as crianças não poderiam sofrer de moléstia contagiosa ou repulsiva; e deveriam ter sido vacinadas contra a varíola (Estado do Rio de Janeiro, 1925).

Já os jardins de infância eram destinados às crianças de 4 a 7 anos de idade. Poderiam ser criados junto aos grupos escolares e escolas normais e seguiam o mesmo ano letivo das escolas primárias. As atividades deveriam ser realizadas no período matutino, das $8 \mathrm{~h}$ às $11 \mathrm{~h}$, com descansos e recreios, e as lições deveriam ser dadas ao ar livre, via processos intuitivos e concretos. Ainda, cada professor adjunto seria responsável por um grupo de até 50 alunos matriculados. Para fins de admissão, a legislação previa que os filhos de operários, domésticos e crianças órfãs de mãe teriam preferência na matrícula, não possuir moléstia contagiosa ou repulsiva e terem sido vacinadas contra varíola (Estado do Rio de Janeiro, 1925).

Se a legislação nos serviu como o primeiro elemento de discussão sobre o estabelecimento da pré-escola no contexto fluminense a partir dela diversos questionamentos passaram a ser pontos de inflexão. Quantas pré-escolas haviam sido criadas a partir de 1925? Sua criação se deu em todas as cidades do estado ou alguma foi privilegiada? Quais e quantas crianças foram atendidas? E os professores? Entre outros questionamentos. Na busca por documentação que nos possibilita-se investir sobre esses questionamentos, em consulta ao Fundo Departamento de Educação do Arquivo Público do Estado do Rio de Janeiro (FDE/APERJ) localizamos os mapas de frequência escolar (voltado para o controle de frequência dos alunos) e mapas de frequência de adjuntos (voltado para o controle da frequência das professoras) dos jardins de infância públicos estaduais criados pelo governo fluminense entre as décadas de 1920 e $1940^{3}$.

Pela leitura e análise dos mapas de frequência escolar e de adjuntos foram contabilizados 19 jardins de infância públicos, criados e financiados pelo governo estadual na primeira metade do século XX em diferentes cidades. Vale ressaltar que é possível que outros jardins de infância e escolas maternais tenham sido criados neste período, porém a contabilidade aqui apresentada se refere aos dados coletados nos mapas de frequência escolar e de adjuntos disponíveis para consulta no FDE/APERJ.

Em Niterói foram contabilizadas cinco instituições, o Jardim de infância de

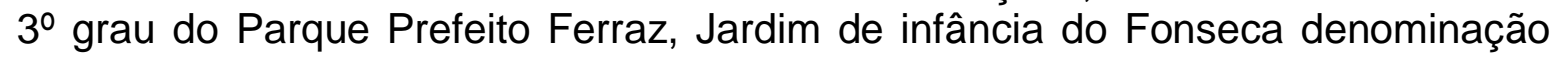
especial Hilário Ribeiro, Jardim de infância anexo ao Grupo Escolar Raul Vidal, 
Jardim de infância da casa maternal $1^{\circ}$ de maio, Jardim de infância na Vila Ipiranga denominação especial Celina. Em Nova Iguaçu foram dois, o Jardim de infância da rua Floriano Peixoto e o Jardim de infância da rua 13 de Maio. Um em Porciúncula, o Jardim de infância anexo ao Grupo Escolar Orlinda Veiga; assim como em Santo Antônio de Pádua, o Jardim de infância de Miracema; em São Fidélis, o Jardim de Infância de São Fidélis n. 1; em Três Rios, Jardim de infância anexo ao Grupo Escola Procópio Aual, denominação especial Celina Vargas do Amaral; em Bom Jesus do Itabapoana, o Jardim de Infância José de Oliveira Borges; e em Miracema, o Jardim de Infância. Por fim, em Campos dos Goytacazes, localidade privilegiada neste trabalho, foram identificados seis instituições, o Jardim de infância anexo ao Grupo Escolar Benta Pereira, Jardim de infância anexo a Escola Modelo Seis de Março, Jardim de infância anexo a Escola Modelo/Grupo Escolar João Pessoa, Jardim de infância da Praça Nilo Peçanha, Jardim de infância da rua Visconde do Rio Branco, Jardim de infância anexo ao Grupo Escolar Saldanha da Gama (ARQUIVO PÚBLICO DO ESTADO DO RIO DE JANEIRO. Fundo Departamento de Educação. Código: 00809 a 00814; caixas 0076 e 00770).

Das cidades listadas, Campos dos Goytacazes (situada na região norte do estado) e Niterói (então capital do estado) se destacaram com o maior quantitativo de jardins de infância públicos. Diante disso, trabalhamos com a hipótese que a existência e trajetória de escolas normais, instituição presente nas cidades de Niterói (Villela, 2002) e Campos (Martínez, Boynard, 2004; Martínez, 2009, 2012), fundadas no decorrer do século XIX e mantidas no século XX, tenham atuado como elemento de influência na especialização educativa, via formação de professores e na defesa da ampliação do atendimento escolar da população. Ainda, é possível considerar que a inserção da educação infantil na estrutura educativa pública estadual fluminense estava vinculada com as discussões de ordem social, a partir da regulamentação da mão de obra feminina e a criação de espaços para o atendimento infantil. Também pode-se relacionar com a proeminência política de Campos e Niterói tenha contribuído para que a estrutura pré-escolar tenha se desenvolvido com mais intensidade que nas outras cidades do estado.

Na próxima seção serão apresentados os mapas de frequência escolar e de adjuntos como fonte de pesquisa para a história da educação infantil fluminense.

\section{Os mapas de frequência escolar e os mapas de frequência de adjuntos como fonte para a história da educação infantil fluminense}

A pesquisa sobre história da educação infantil pública fluminense na primeira metade do século XIX constitui uma lacuna no campo da história da educação, tendo em vista que as discussões sobre a escolarização primária, secundária e profissional ocupam lugar privilegiado entre as produções existentes. Enfrentar a temática por meio da análise dos mapas de frequência escolar, de frequência de apresentou-se como uma possibilidade de identificar dados, como o quantitativo de alunos matriculados, quantitativo de profissionais que atuavam em cada instituição escolar, eventos de ordem natural ou social que interferiam na rotina escolar, bem como outros registros que fornecem informações a respeito da dinâmica da educação pré-escolar no contexto espaço-temporal selecionado. 
Como apontado por Faria Filho et al (2005), Gouveia (2006) e Vidal (2007), em um contexto ampliado, a estatística (escolar) surgiu no início do século XIX como dispositivo que visava tanto compreender racionalmente as relações sociais, como representa-las ou produzi-las, ao, simultaneamente, nomear, classificar e hierarquizar os sujeitos e a realidade social. No mesmo sentido, Dias $(2013,2014)$ classifica o mapa de frequência escolar no estado do Rio de Janeiro como um documento de ordem administrativa-pedagógica, utilizado para pelo serviço de inspeção escolar e para a produção de estatísticas do ensino. Para a autora, "mais do que buscar mensurar uma realidade, procurava instituí-la ao definir critérios para a criação e permanência de escolas, ao subsidiar as iniciativas para o funcionamento do ensino, o povoamento das escolas e a distribuição do magistério" (Dias, 2014, p. 123).

Como apontou Dias (2014), os mapas de frequência escolar não devem ser considerados como quadro representativo da totalidade das escolas existentes na região. É possível, durante a trajetória do acervo documental, ocorrerem interferências oriundas do processo de coleta e preservação dos arquivos, fator que pode ocultar outras instituições que tenham existido. Dessa maneira, o quantitativo apresentado neste artigo refere-se a levantamento feito a partir de um composto documental oficial específico localizado no FDE/APERJ, e não se ignora a possibilidade da existência de outros jardins de infância públicos estaduais no contexto da primeira metade do século XX.

No contexto fluminense, os mapas de frequência escolar e de frequência dos adjuntos eram preenchidos pela direção da escola ou professor designado por ela. Ao final do mês letivo, com data limite de até três dias do seu encerramento, eles deveriam ser enviados ao serviço de inspeção estadual. Caso não fossem, o funcionário responsável pelo envio teria descontado de seus honorários os dias referentes ao atraso. Os mapas eram produzidos em triplicata, sendo uma via remetida à diretoria de Instrução Pública que serviria para a produção da estatística escolar; outra à Inspetoria Regional, que serviria como base da atestação do exercício mensal do magistério e dos profissionais que atuavam na escola; e a terceira se mantinha arquivada na unidade escolar.

Os dados presentes nos mapas de frequência escolar referem-se ao fluxo de alunos matriculados (ingressos, egressos e frequência diária e média mensal); quantitativo de professores (efetivos, estagiários, interinos, substitutos, extranumerários); e informações relativas ao registro de visitas de autoridades e turno de funcionamento. Em 1933, o documento sofreu alteração e passou a comportar em seu verso o mapa de frequência de adjuntos, dedicado a coletar dados sobre os profissionais que atuavam nas escolas, o nome, quantidade de turmas sob sua responsabilidade e número de alunos matriculados, bem como a média de frequência mensal e espaço para o registro de faltas e observações. É possível supor que a especialização da estatística escolar, ao coletar dados sobre os trabalhadores que atuavam nas unidades escolares, esteja relacionada com a reforma da instrução pública fluminense de 1933, pelo decreto n. 2.922 de reorganização da Diretoria da Instrução Pública para Departamento da Educação e Iniciação ao Trabalho ${ }^{4}$. A reforma teve como propósito reorganizar a estrutura educativa administrativa fluminense, a partir de funcionários técnicos em prol da renovação educativa, orientação e fiscalização técnica e profissional (Correio da Manhã, 27/6/1933, n. 11.830, p. 2).

Além de informações referentes ao controle de matrícula e frequência de alunos e profissionais, os mapas trazem informações referentes ao cotidiano institucional, como justificativas das faltas de alunos, motivos de ausência de 
profissionais e aspectos de ordem social que afetavam o dia a dia escolar. A queda na frequência média dos alunos, por exemplo, foi justificada por conta de surtos de sarampo e catapora, por dias de chuva e festividades cívica ou religiosa (festa do padroeiro e recepção do bispo), entre outras. Já a ausência das trabalhadoras se referia a licenças especiais, motivos de doença ou afastamento para capacitação profissional. Esses foram os casos, por exemplo, da inspetora de alunos Dalila Costa, afastada entre os dias 12 a 25 de julho de 1948 pela Divisão Sanitária; e da professora Maria Odete Bazin Grevy Bastos, que entre os dias 12 a 18 daquele mês esteva afastada para participar de um curso de especialização no Distrito Federal.

A partir dos mapas de frequência escolar e de adjuntos foi possível construir um panorama sobre os jardins de infância públicos campistas. Foram identificados o nome das professoras e funcionários; contabilizados o número de trabalhadores e de matrículas em cada instituição escolar; e identificados eventos de ordem natural e social que interferiram na rotina dos jardins de infância. Pelo volume de dados, optou-se por apresentá-los a partir de tabelas comentadas, de modo a favorecer a percepção sobre a estrutura de cada instituição.

Importante destacar a fragmentação e incompletude do conjunto documental manuseado. Existem lacunas entre os anos e os meses no período investigado, que variam de instituição para instituição. Por esse motivo, e sem demérito do presente estudo, para exame comparativo aprofundado das características de cada escola infantil seria necessário o manuseio de dados mais robustos e em série.

A análise se apoia em uma perspectiva teórica oriunda da História Social da Educação, considerando os sujeitos como agentes históricos que produzem suas experiências cotidianas entre ideias em circulação, conflitos de interesses e convicções compartilhadas. Tal perspectiva está interessada em um possível afastamento de uma postura paternalista para responder sobre a implementação da pré-escola pública. Ou seja, considera-se o Estado como provedor de instituições e mecanismo de inserção social da população, ao passo que suas ações são ocasionadas por demandas da população, de modo de codependência do processo histórico (Bertucci, Faria Filho, Oliveira, 2010; Thompson, 2011).

Na seção a seguir apresentamos os dados coletados e sistematizados bem como uma discussão sobre os números e elementos descritivos e informativos identificados na documentação.

\section{Os jardins de infância públicos estaduais em Campos dos Goytacazes}

De acordo com Boynard (2006), o primeiro jardim de infância público de Campos dos Goytacazes foi criado em 1923, anexo à Escola Modelo da Escola Normal de Campos, por ação da professora Antonia Ribeiro de Castro Lopes ${ }^{5}$. Contudo, até o início da década de 1930 o seu funcionamento foi intermitente por falta de pessoal específico ou por questões materiais.

Os mapas escolares do Jardim de Infância anexo à Escola Modelo Seis de Março disponíveis no FDE/APERJ, relativos ao ano de 1931, cobrem apenas os meses de junho a novembro de 1931 (Tabela 1). Mas são suficientes para identificar algumas características interessantes do seu funcionamento. 
Tabela 1: Número de matrículas no Jardim de Infância anexo à Escola Modelo

Seis de Março

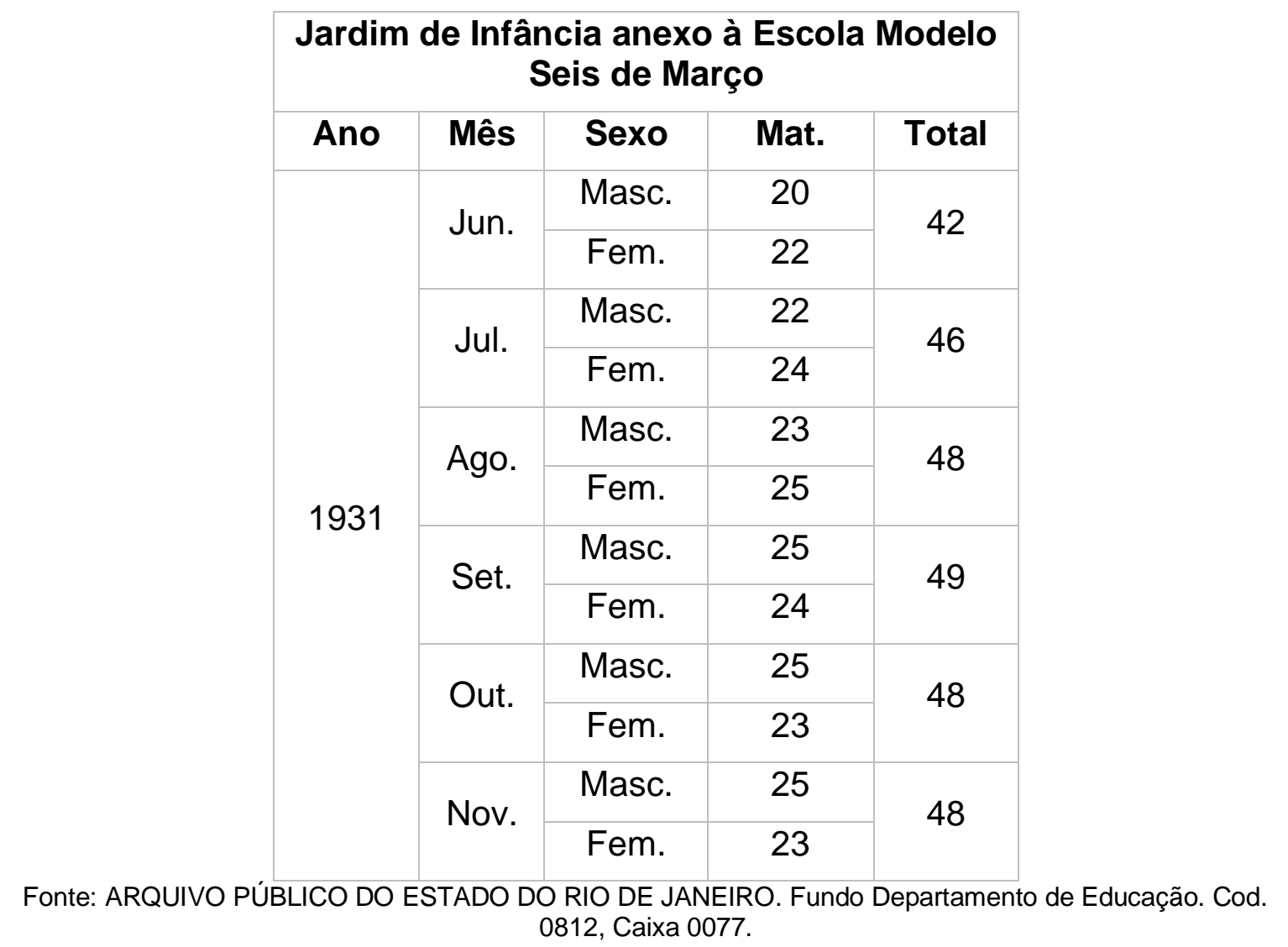

Duas professoras, uma adjunta e uma efetiva, eram responsáveis pelas crianças matriculadas. As atividades pedagógicas ocorriam no turno matutino, das $8 \mathrm{~h}$ às $11 \mathrm{~h}$, divididas entre descansos e recreios. Os alunos eram divididos em 3 classes $^{6}$, de acordo com suas faixas etárias, agrupados entre alunos de 4 a 5 anos, 5 a 6 anos e 6 a 7 anos, como previsto pelo Decreto n. 2.105 (Estado do Rio de Janeiro, 1925). Das professoras, a única que teve seu nome registrado foi Maria Manhães Corrêa ${ }^{7}$, que assinou como professora efetiva da Escola Modelo e diretora do Jardim de Infância.

Um fato que chama a atenção foi o registro de alunos classificados como "analfabetos". No mês de junho contabilizou-se 1 aluno analfabeto; em julho, 4 alunos; em agosto, 3 alunos e em setembro 2 alunos. A presença dessa tipologia nos mapas escolares nos leva a supor que a perspectiva pedagógica implementada no jardim de infância tinha um caráter voltado para a escolarização/alfabetização inicial dos sujeitos.

No final de 1931 houve o encerramento das atividades deste jardim de infância e da Escola Modelo à qual estava anexo. Embora não tenha sido localizado o motivo na documentação manuseada, Boynard (2006) indica que a Escola Modelo Seis de março foi transformada em Grupo Escolar João Pessoa pelo decreto no 2.676, de 17 de novembro de 1931. 
Referente a nova organização assumida em 1932, os mapas de frequência escolar e de adjuntos, referentes ao Jardim de Infância anexo ao Grupo Escolar João Pessoa, contemplam até o ano 1934 de modo intermitente ${ }^{8}$. Nos meses quantificados é possível observar que o número de crianças matriculadas cresceu de forma progressiva. No mês de março de 1932, por exemplo, foram contabilizadas 43 crianças matriculadas. Já no último mês documentado, outubro de 1934, registraram-se 94 matrículas, que correspondiam a 47 de cada sexo (Tabela 2).

Tabela 2: Número de matrículas no Jardim de Infância anexo a Escola Modelo João Pessoa

\begin{tabular}{|c|c|c|c|c|c|c|c|}
\hline \multicolumn{8}{|c|}{ Jardim de Infância anexo a Escola Modelo/Grupo Escolar João Pessoa } \\
\hline \multirow[b]{2}{*}{ Mês } & \multirow[b]{2}{*}{ Sexo } & \multicolumn{2}{|c|}{1932} & \multicolumn{2}{|c|}{1933} & \multicolumn{2}{|c|}{1934} \\
\hline & & Mat. & Total & Mat. & Total & Mat. & Total \\
\hline \multirow{2}{*}{ Mar. } & Masc. & 20 & \multirow{2}{*}{43} & 26 & \multirow{2}{*}{48} & 32 & \multirow{2}{*}{62} \\
\hline & Fem. & 23 & & 22 & & 30 & \\
\hline \multirow{2}{*}{ Abr. } & Masc. & 24 & \multirow{2}{*}{55} & 30 & \multirow{2}{*}{59} & 41 & \multirow{2}{*}{76} \\
\hline & Fem. & 31 & & 29 & & 35 & \\
\hline \multirow{2}{*}{ Mai. } & Masc. & 30 & \multirow{2}{*}{61} & 32 & \multirow{2}{*}{62} & 41 & \multirow{2}{*}{77} \\
\hline & Fem. & 31 & & 30 & & 36 & \\
\hline \multirow{2}{*}{ Jun. } & Masc. & 30 & \multirow{2}{*}{60} & 35 & \multirow{2}{*}{71} & 41 & \multirow{2}{*}{78} \\
\hline & Fem. & 30 & & 36 & & 37 & \\
\hline \multirow{2}{*}{ Jul. } & Masc. & 37 & \multirow{2}{*}{70} & 39 & \multirow{2}{*}{76} & 42 & \multirow{2}{*}{79} \\
\hline & Fem. & 33 & & 37 & & 37 & \\
\hline \multirow{2}{*}{ Ago. } & Masc. & 38 & \multirow{2}{*}{71} & 38 & \multirow{2}{*}{79} & 42 & \multirow{2}{*}{84} \\
\hline & Fem. & 33 & & 41 & & 42 & \\
\hline \multirow{2}{*}{ Set. } & Masc. & 38 & \multirow{2}{*}{69} & 38 & \multirow{2}{*}{78} & 47 & \multirow{2}{*}{93} \\
\hline & Fem. & 31 & & 40 & & 46 & \\
\hline \multirow{2}{*}{ Out. } & Masc. & 37 & 68 & 38 & 79 & 47 & O4 \\
\hline & Fem. & 31 & . & 41 & & 47 & \\
\hline & Masc. & 36 & fr & 38 & 70 & $x$ & \\
\hline & Fem. & 30 & & 41 & & $x$ & 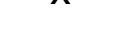 \\
\hline
\end{tabular}

Fonte: ARQUIVO PÚBLICO DO ESTADO DO RIO DE JANEIRO. Fundo Departamento de Educação. Cod. 0809, Caixa 0077.

De acordo com anotação no mapa de frequência de adjuntos, em maio de 1933, a professora Maria Manhães Corrêa, que havia atuado no jardim de infância anexo à Escola Modelo Seis de Março, foi incorporada ao Jardim de infância anexo ao Grupo Escolar João Pessoa como professora e diretora efetiva. A manutenção da professora desde os tempos do jardim de infância anexo à Escola Modelo reforça a informação que o fechamento da pré-escola deu origem àquela que foi criada no Grupo Escolar João Pessoa, como apontado Boynard (2006). Ao lado dela, atuava 
a professora adjunta Rosalina Lacourt da Cruz. A alta densidade de matrículas no jardim de infância foi uma realidade durante todo o ano de 1933, no qual o pico de crianças matriculadas foi registrado em outubro de 1934 com 94 crianças (Tabela 2). Maria e Rosalina dividiam as tarefas. A primeira atuava com os $2^{\circ}$ e $3^{\circ}$ períodos, e a segunda com o primeiro período que possuía o maior quantitativo de crianças matriculadas.

Na coluna "observações" do mapa de frequência de adjuntos foi registrado a partir de maio de 1933 que a diretora também lecionava. Tal informação pode ser entendida como um indício de uma possível sinalização à Diretoria da Instrução Pública e/ou à Inspetoria Regional pela demanda por mais professores para atuar na pré-escola (Arquivo Público do Estado do Rio de Janeiro. Fundo Departamento de Educação. Dossiê 809, maio de 1933). Isso pois, pela reconfiguração educativa implementada em 1933, pelo Decreto n. 2.930, cada professora deveria ser responsável por no máximo 25 crianças, o que, de acordo com os números registrados nos mapas, era significativamente ultrapassado (Estado do Rio de Janeiro, 1933). A saber, de acordo com o Decreto n. 2.105 de 1925, era calculado na proporção de 1 professora para 50 alunos matriculados (Estado do Rio de Janeiro, 1925).

No bojo da reconfiguração da instrução pública fluminense implementadas pelo decreto n. 2.923 de 1933, foi publicado o decreto n. 2.930 no mesmo ano, especificamente voltado para a questão das organizações pré-escolares. O Decreto "das Organizações pré-escolares" tratou com mais esmero das casas maternais e jardins de infância, designando o público alvo, objetivos, funções, modos de funcionamento, formação de professores no interior desses espaços e ainda o que tange à contratação de professores via concurso público, fator não previsto pela legislação de 1925 (Estado do Rio de Janeiro, 1933).

Nos primeiros meses de 1934, o quadro de professoras do Jardim de infância anexo ao Grupo Escolar João Pessoa se manteve desfalcado. Em junho assumiu a professora Aldarina da Penha Carneiro como adjunta e o quantitativo de 78 alunos matriculados foi dividido entre o corpo docente. Rosalina ficou responsável pelo grupo de $1^{\circ}$ período, com 35 alunos; Aldarina, com o 2ำ período, com 24 alunos; e Maria com 17 alunos. No mês seguinte passou a integrar o grupo docente Lucilia Miranda que assumiu o grupo que estava sob responsabilidade da diretora.

Por não sabermos se a instituição tinha encerrado suas atividades em 1934 ou se os documentos aos anos subsequentes não haviam sido preservados, associamos a análise dos mapas escolares e de adjuntos às notícias de jornais fluminenses disponibilizados em formato digitalizado pela Hemeroteca Digital da Biblioteca Nacional (HDBN). Assim, localizamos em 1936 no jornal "Correio da Manhã" que, por conta da precária estrutura física da escola que ameaçava ruir, o jardim de infância foi fechado (Correio da Manhã, 18/9/1936, p. 3, no․ 12.838; A Noite, 18/9/1936, p. 5, nº. 08852). Desta forma, foi possível chegar à conclusão que as atividades do jardim de infância foram interrompidas.

Não conseguimos localizar informações sobre o destino das crianças e das professoras com o fechamento do jardim de infância, tanto na documentação oficial manuseada como na imprensa. Dessa forma, a partir da análise dos outros mapas de frequência escolar e de adjuntos criamos uma listagem com o nome das professoras e identificamos às instituições para onde foram remanejadas. Pelo levantamento e cruzamento das informações foi possível considerar que o Jardim de infância anexo ao Grupo Escolar João Pessoa deu origem ao Jardim de Infância da rua Visconde do Rio Branco, cuja documentação se inicia em 1937 (ano seguinte 
ao fechamento do jardim de infância anexo ao Grupo Escolar João Pessoa) e finaliza em 1942. Esse conjunto documental também é incompleto.

Pelas informações coletadas nos mapas escolares e de frequência de adjuntos foi possível identificar um quantitativo maior de crianças matriculadas que nas duas instituições anteriores, como pode ser percebido na tabela 4. Entre 1937 a 1942 a maior incidência de matrículas foi registrada no ano de 1940 com 250 matrículas, onde o número de meninas era ligeiramente superior ao de meninos.

Tabela 3: Número de matrículas do Jardim de Infância da rua Visconde do Rio Branco (1937-1942)

\begin{tabular}{|c|c|c|c|c|c|c|c|c|c|}
\hline \multicolumn{10}{|c|}{ Jardim de Infância da rua Visconde do Rio Branco } \\
\hline \multirow[b]{2}{*}{ Mês } & \multirow[b]{2}{*}{ Sexo } & \multicolumn{2}{|c|}{1937} & \multicolumn{2}{|c|}{1939} & \multicolumn{2}{|c|}{1940} & \multicolumn{2}{|c|}{1942} \\
\hline & & Mat. & Total & Mat. & Total & Mat. & Total & Mat. & Total \\
\hline \multirow{2}{*}{ Mar. } & Masc. & $x$ & \multirow{2}{*}{$\mathrm{x}$} & 92 & \multirow{2}{*}{194} & 108 & \multirow{2}{*}{211} & 50 & \multirow{2}{*}{112} \\
\hline & Fem. & $\mathrm{x}$ & & 102 & & 103 & & 62 & \\
\hline \multirow{2}{*}{ Abr. } & Masc. & $\mathrm{x}$ & \multirow{2}{*}{$\mathrm{x}$} & 92 & \multirow{2}{*}{194} & 108 & \multirow{2}{*}{203} & 57 & \multirow{2}{*}{128} \\
\hline & Fem. & $x$ & & 102 & & 95 & & 71 & \\
\hline \multirow{2}{*}{ Mai. } & Masc. & $x$ & \multirow{2}{*}{$x$} & 92 & \multirow{2}{*}{194} & 125 & \multirow{2}{*}{235} & 62 & \multirow{2}{*}{139} \\
\hline & Fem. & $x$ & & 102 & & 110 & & 77 & \\
\hline \multirow{2}{*}{ Jun. } & Masc. & $x$ & \multirow{2}{*}{$x$} & 92 & \multirow{2}{*}{194} & 119 & \multirow{2}{*}{232} & 63 & \multirow{2}{*}{140} \\
\hline & Fem. & $x$ & & 102 & & 113 & & 77 & \\
\hline \multirow{2}{*}{ Jul. } & Masc. & 66 & \multirow{2}{*}{145} & 108 & \multirow{2}{*}{226} & 128 & \multirow{2}{*}{244} & $x$ & \multirow{2}{*}{$x$} \\
\hline & Fem. & 79 & & 118 & & 116 & & $x$ & \\
\hline \multirow{2}{*}{ Ago. } & Masc. & 61 & \multirow{2}{*}{143} & 108 & מכ2 & 124 & 230 & $x$ & v \\
\hline & Fem. & 72 & & 118 & $\angle<0$ & 114 & $\angle 00$ & $x$ & $x$ \\
\hline Set & Masc. & $x$ & $x$ & 108 & 226 & 126 & 244 & $x$ & $x$ \\
\hline sel. & Fem. & $x$ & $x$ & 118 & $\angle<0$ & 118 & & $x$ & $x$ \\
\hline Out & Masc. & 53 & & 108 & אכ2 & 128 & 250 & $x$ & \\
\hline ut. & Fem. & 67 & $x$ & 118 & $\angle \angle 0$ & 122 & $\angle 00$ & $x$ & $X$ \\
\hline & Masc. & 41 & $y$ & 108 & 226 & 128 & 250 & $x$ & y \\
\hline INov. & Fem. & 43 & X & 118 & $<<0$ & 122 & $<0$ & $x$ & X \\
\hline
\end{tabular}

Fonte: ARQUIVO PÚBLICO DO ESTADO DO RIO DE JANEIRO. Fundo Departamento de Educação. Cod. 0814, Caixa 0077.

Assim como o número ampliado de matrículas, o quantitativo de trabalhadoras no Jardim de Infância da rua Visconde do Rio Branco era maior que as duas instituições anteriores, o que indica a busca por um equilíbrio com o número de alunos (Tabela 4). O último mapa desta instituição é referente ao mês de junho, que, seguindo a estrutura do calendário escolar, era o mês anterior ao recesso do meio do ano. Neste mapa, embora não haja registro se a instituição seria transferida 
para outro espaço ou se suas atividades seriam encerradas, a coluna "Observações" aponta que as professoras Aldarina da Penha Carneiro e Dagmar Ribeiro Brandão foram transferidas provisoriamente, porém não há indicação para qual estabelecimento. Já as demais funcionárias, a substituta Hyné Mendes Quintas e as guardiãs Leônia Paula Rebel e Maria Carlota de Carvalho, só que haviam atuado no jardim de infância até o dia 2 de junho daquele ano.

Tabela 4: Quantitativo e categorias profissional do Jardim de Infância da Rua Visconde do Rio Branco

\section{Jardim de Infância da rua Visconde do Rio Branco}

\begin{tabular}{|c|c|c|c|c|c|c|c|c|c|c|}
\hline Ano & $\begin{array}{l}\text { Categoria } \\
\text { Profissional }\end{array}$ & Mar & Abr & Mai & Jun & Jul & Ago & Set & Out & Nov \\
\hline \multirow{5}{*}{1937} & Prof. efetiva & * & * & * & * & * & 7 & 7 & 7 & 7 \\
\hline & Prof. substituta & * & * & * & * & * & 1 & 1 & 1 & 1 \\
\hline & Guardiã & * & * & * & * & * & 5 & 5 & 6 & 6 \\
\hline & Servente & * & * & * & * & * & 2 & 2 & 2 & 2 \\
\hline & Total & * & * & * & * & * & 15 & 15 & 16 & 16 \\
\hline \multirow{5}{*}{1939} & Prof. efetiva & 5 & 5 & 6 & 6 & 6 & 6 & 6 & 6 & 6 \\
\hline & Prof. substituta & * & 1 & 1 & 1 & * & * & * & * & * \\
\hline & Guardiã & 5 & 5 & 5 & 5 & 5 & 5 & 5 & 5 & 5 \\
\hline & Servente & 2 & 1 & 1 & 1 & 1 & 1 & 1 & 1 & 1 \\
\hline & Total & 10 & 12 & 13 & 13 & 12 & 12 & 12 & 12 & 12 \\
\hline \multirow{5}{*}{1940} & Prof. efetiva & 7 & 7 & 6 & 6 & 6 & 6 & 7 & 7 & 7 \\
\hline & Prof. substituta & * & * & * & * & * & * & 1 & 1 & 1 \\
\hline & Guardiã & 5 & 5 & 5 & 5 & 5 & 5 & 6 & 6 & 6 \\
\hline & Servente & 1 & 1 & 1 & 1 & 1 & 1 & 1 & 1 & 1 \\
\hline & Total & 13 & 13 & 12 & 12 & 12 & 12 & 15 & 15 & 15 \\
\hline \multirow{5}{*}{1942} & Prof. efetiva & 7 & 7 & 7 & 6 & * & * & * & * & * \\
\hline & Prof. substituta & * & * & 1 & 1 & * & * & * & * & * \\
\hline & Guardiã & 6 & 6 & 6 & 6 & * & * & * & * & * \\
\hline & Servente & 1 & 1 & 1 & * & * & * & * & * & * \\
\hline & Total & 14 & 14 & 15 & 12 & * & * & * & * & * \\
\hline
\end{tabular}

Fonte: ARQUIVO PÚBLICO DO ESTADO DO RIO DE JANEIRO. Fundo Departamento de Educação. Cod. 0814, Caixa 0077.

As categorias de professores identificadas no decorrer da pesquisa nos apontam para uma diversidade e complexidade existente na categoria docente pertencente à administração pública estadual. Como pode ser observado no manuseio da documentação em determinado momento os professores eram categorizados como efetivos, substitutos, auxiliares e extranumerária. Já em outro, a categoria utilizada era "padrão C", para professores do ensino pré-primário e primário. Cada categoria correspondia a uma gradação na carreira do magistério e 
com a estrutura administrativa das gestões governamentais, sobre as quais incidiam os salários e se relacionava com o tempo de serviço. Além das professoras, os jardins de infância com maior quantidade de matrículas acomodavam outras profissionais como guardiãs, serventes, inspetor de alunos e auxiliares de saúde que não eram diplomados como os cargos de professor, e que auxiliavam nas rotinas escolares, tanto no trato com as crianças como na limpeza e organização dos espaços.

Das instituições analisadas, o Jardim de Infância da praça Nilo Peçanha foi a instituição escolar que teve a maior quantidade de mapas de frequência escolar e de adjuntos arquivados no APERJ. Ao todo são 27 mapas que abarcam o período de 1934 a 1940. Ele foi instalado em um prédio existente em que outrora havia funcionado a Escola ao Ar Livre Wencesláo Braz ${ }^{9}$ até ano de 1934, e em 1943 encerrou suas atividades por conta da insuficiência de recursos (Rosselini, 2019)

Junto com o Jardim de Infância da rua Visconde do Rio Branco, o da Praça Nilo Peçanha apresenta um alto número de matrículas. A título de percepção da ampliação do número de crianças, o Jardim saltou de 122 matrículas em agosto de 1934 para 413 em abril de 1940 (Tabela 5).

Tabela 5: Números de matrículas no Jardim de Infância à Praça Nilo Peçanha (1934-1940)

\begin{tabular}{|c|c|c|c|c|c|c|c|c|c|c|c|}
\hline \multicolumn{12}{|c|}{ Jardim de Infância da Praça Nilo Peçanha } \\
\hline & & \multicolumn{2}{|c|}{1934} & \multicolumn{2}{|c|}{1936} & \multicolumn{2}{|c|}{1937} & \multicolumn{2}{|c|}{1939} & \multicolumn{2}{|c|}{1940} \\
\hline Mês & Sexo & Mat. & Total & Mat. & total & Mat. & Total & Mat. & total & Mat. & total \\
\hline \multirow{2}{*}{ Mar. } & Masc. & $x$ & \multirow{2}{*}{$x$} & 41 & \multirow{2}{*}{102} & 39 & \multirow{2}{*}{95} & 77 & \multirow{2}{*}{171} & 158 & \multirow{2}{*}{320} \\
\hline & Fem. & $x$ & & 61 & & 55 & & 94 & & 162 & \\
\hline \multirow{2}{*}{ Abr. } & Masc. & $x$ & \multirow{2}{*}{$x$} & $x$ & \multirow{2}{*}{$\mathrm{x}$} & 66 & \multirow{2}{*}{148} & 91 & \multirow{2}{*}{206} & 203 & \multirow{2}{*}{413} \\
\hline & Fem. & $x$ & & $x$ & & 82 & & 115 & & 210 & \\
\hline \multirow{2}{*}{ Mai. } & Masc. & $x$ & \multirow{2}{*}{$x$} & $x$ & \multirow{2}{*}{$x$} & 78 & \multirow{2}{*}{$x$} & 107 & \multirow{2}{*}{247} & 185 & \multirow{2}{*}{370} \\
\hline & Fem. & $x$ & & $x$ & & $x$ & & 140 & & 185 & \\
\hline \multirow{2}{*}{ Jun. } & Masc. & $x$ & \multirow{2}{*}{$x$} & $x$ & \multirow{2}{*}{$x$} & 82 & \multirow{2}{*}{178} & 101 & \multirow{2}{*}{232} & 149 & \multirow{2}{*}{304} \\
\hline & Fem. & $x$ & & $x$ & & 96 & & 131 & & 155 & \\
\hline \multirow{2}{*}{ Jul. } & Masc. & $x$ & \multirow{2}{*}{$\mathrm{x}$} & 100 & \multirow{2}{*}{200} & 89 & 105 & 105 & קחת & 161 & \\
\hline & Fem. & $x$ & & 100 & & 106 & 100 & 127 & 20 & 171 & Go \\
\hline Agn & Masc. & 66 & 122 & 107 & 216 & 93 & 198 & 108 & 236 & $x$ & $\mathrm{x}$ \\
\hline rigo. & Fem. & 56 & $1<<$ & 109 & 610 & 105 & 100 & 128 & 200 & $x$ & $\lambda$ \\
\hline Set & Masc. & 85 & 162 & $x$ & $x$ & $x$ & $x$ & 99 & 211 & $x$ & $\mathrm{y}$ \\
\hline . & Fem. & 77 & & $x$ & & $x$ & & 112 & & $x$ & \\
\hline Out & Masc. & 94 & 181 & $x$ & $\mathrm{y}$ & $x$ & $\mathrm{y}$ & 91 & 184 & $x$ & $\mathrm{x}$ \\
\hline . & Fem. & 87 & ו & $x$ & $\hat{n}$ & $x$ & n & 93 & דם & $x$ & \\
\hline & Masc. & 100 & & $x$ & & $x$ & & 90 & & $x$ & \\
\hline TOU. & Fem. & 96 & שת & $x$ & ^ & $x$ & ^ & 83 & 110 & $x$ & $x$ \\
\hline
\end{tabular}

Fonte: ARQUIVO PÚBLICO DO ESTADO DO RIO DE JANEIRO. Fundo Departamento de Educação. Cod. 0810, Caixa 0077. 
Tabela 6: Quantidade e categoria de profissionais do Jardim de Infância à Praça Nilo Peçanha

\begin{tabular}{|c|c|c|c|c|c|c|c|c|c|c|}
\hline \multicolumn{11}{|c|}{ Jardim de Infância à Praça Nilo Peçanha } \\
\hline Ano & $\begin{array}{c}\text { Categoria } \\
\text { Profissional }\end{array}$ & Mar & Abr & Mai & Jun & Jul & Ago & Set & Out & Nov \\
\hline \multirow{3}{*}{1934} & Prof. efetiva & $x$ & $\mathrm{x}$ & $\mathrm{x}$ & $\mathrm{x}$ & $x$ & 2 & 2 & 3 & 10 \\
\hline & Guardiã & $\mathrm{x}$ & $\mathrm{x}$ & $\mathrm{x}$ & $\mathrm{x}$ & $x$ & $x$ & $\mathrm{x}$ & 1 & 1 \\
\hline & Total & $\mathbf{x}$ & $\mathbf{x}$ & $\mathbf{x}$ & $\mathbf{x}$ & $\mathbf{x}$ & 2 & 2 & 4 & 11 \\
\hline \multirow{5}{*}{1936} & Prof. efetiva & 9 & $x$ & $x$ & $x$ & 8 & 10 & $x$ & $x$ & $x$ \\
\hline & $\begin{array}{c}\text { Prof. } \\
\text { substituta }\end{array}$ & 1 & $x$ & $x$ & $x$ & 3 & 2 & $x$ & $x$ & $x$ \\
\hline & Guardiã & 4 & $x$ & $x$ & $x$ & 5 & 5 & $x$ & $x$ & $x$ \\
\hline & Servente & 2 & $x$ & $x$ & $x$ & 2 & 2 & $x$ & $x$ & $x$ \\
\hline & Total & 16 & & & & 18 & 19 & $\mathbf{x}$ & $\mathbf{x}$ & $x$ \\
\hline \multirow{5}{*}{1937} & Prof. efetiva & 6 & 10 & 11 & 11 & 11 & 9 & $x$ & $x$ & $x$ \\
\hline & $\begin{array}{c}\text { Prof. } \\
\text { substituta }\end{array}$ & 5 & 6 & 2 & 2 & 2 & 2 & $x$ & $x$ & $x$ \\
\hline & Guardiã & 5 & 5 & 5 & 5 & 5 & 6 & $x$ & $x$ & $x$ \\
\hline & Servente & 2 & 2 & 2 & 2 & 2 & 1 & $x$ & $x$ & $x$ \\
\hline & Total & 18 & 23 & 20 & 20 & 20 & 18 & $x$ & $\mathbf{x}$ & $\mathbf{x}$ \\
\hline \multirow{6}{*}{1939} & Prof. efetiva & 11 & 10 & 10 & 10 & 10 & 10 & 10 & 10 & 10 \\
\hline & $\begin{array}{c}\text { Prof. } \\
\text { substituta }\end{array}$ & $x$ & 1 & 3 & 4 & 4 & 3 & 2 & 2 & 2 \\
\hline & Guardiã & 7 & 7 & 8 & 8 & 8 & 8 & 8 & 7 & 8 \\
\hline & Aux. Saúde & $x$ & 1 & 1 & 1 & 1 & 1 & 1 & 1 & 1 \\
\hline & Servente & 4 & 2 & 2 & 1 & 1 & 1 & 1 & 1 & 1 \\
\hline & Total & 22 & 21 & 24 & 24 & 24 & 23 & 22 & 21 & 22 \\
\hline \multirow{6}{*}{1940} & Prof. Efetiva & 14 & 13 & 13 & 13 & 13 & $x$ & $x$ & $x$ & $x$ \\
\hline & $\begin{array}{c}\text { Prof. } \\
\text { substituta }\end{array}$ & 3 & 5 & 4 & 3 & 3 & $x$ & $x$ & $x$ & $x$ \\
\hline & Guardiã & 11 & 11 & 11 & 11 & 11 & $x$ & $x$ & $x$ & $x$ \\
\hline & Aux. Saúde & 1 & 1 & 1 & 1 & 1 & $x$ & $x$ & $x$ & $x$ \\
\hline & Servente & 1 & 2 & 2 & 2 & 2 & $x$ & $x$ & $x$ & $x$ \\
\hline & Total & 30 & 32 & 31 & 30 & 30 & $\mathbf{x}$ & $x$ & $\mathbf{x}$ & $\mathbf{x}$ \\
\hline
\end{tabular}

Fonte: ARQUIVO PÚBLICO DO ESTADO DO RIO DE JANEIRO. Fundo Departamento de Educação. Cod. 0810, Caixa 0077. 
Em comparação entre as tabelas 5 e 6 , embora o primeiro mês de cobertura do mapa escolar (agosto de 1934) indique a existência de 122 matrículas, no mapa de frequência dos adjuntos só consta o registro de duas profissionais, a professora adjunta Gracila Fernandes, e a diretora interina Maria Geny Ferreira da Silva ${ }^{10}$. No mês de novembro do mesmo ano as matrículas alcançaram a marca de 196 alunos e o corpo de profissionais passou a 11, com 10 professoras adjuntas e uma guardiã.

Em número de registro de matrículas, o Jardim de Infância da praça Nilo Peçanha foi o maior de Campos. Uma hipótese para a grande quantidade de crianças matriculadas pode estar vinculada à localidade do estabelecimento de ensino, próximo ao centro da cidade. Para dar conta do grande contingente de crianças era necessário um exército de profissionais formado por professoras, guardiãs, serventes e auxiliares de saúde. Como pode ser verificado na tabela 7,0 número de profissionais que atuaram no Jardim de Infância cresceu de acordo com a demanda de matrículas escolares que a instituição recebia, atingindo o pico de 32 funcionários em abril de 1940.

Um pouco distante do centro da cidade foi criado em 1947 o Jardim de Infância José do Patrocínio anexado ao Grupo Escolar Saldanha da Gama, localizado na avenida 28 de março, n.. 33, no bairro Turf Club. A documentação consultada refere-se a dois anos letivos de funcionamento, 1948 e 1949.

Pelos dados, o menor quantitativo de matrículas registradas no jardim de infância foi no primeiro semestre de 1948, totalizando 50, e o maior quantitativo refere-se ao mês de agosto de 1949, onde foram contabilizadas 146 crianças matriculadas (Tabela 7). A direção da escola esteve a cargo da professora Maria Odete Bazin Grevy Bastos, que havia atuado como professora no jardim de infância à Praça Nilo Peçanha entre os anos de 1936 e 1940.

Tabela 7: Número de matrículas do Jardim de Infância anexo ao Grupo Escolar Saldanha da Gama

\begin{tabular}{|c|c|c|c|c|c|}
\hline \multicolumn{8}{|c|}{ Jardim de Infância anexo ao Grupo Escolar Saldanha da Gama } \\
\hline \multirow{2}{*}{ Mês } & Sexo & Mat. & Total & Mat. & Total \\
\hline \multirow{2}{*}{ Mar. } & Masc. & 25 & 50 & 49 & \multirow{2}{*}{100} \\
\cline { 2 - 3 } & Fem. & 25 & & 51 & \\
\hline \multirow{2}{*}{ Abr. } & Masc. & 25 & \multirow{2}{*}{50} & 53 & \multirow{2}{*}{104} \\
\hline \multirow{2}{*}{ Mai. } & Fem. & 25 & & 51 & \\
\hline \multirow{2}{*}{ Jun. } & Masc. & 25 & \multirow{2}{*}{50} & 57 & \multirow{2}{*}{113} \\
\hline \multirow{2}{*}{ Jul. } & Fem. & 25 & & 56 & \\
\hline & Masc. & 25 & \multirow{2}{*}{50} & 70 & \multirow{2}{*}{141} \\
\cline { 2 - 3 } & Fem. & 25 & & 71 & \\
\hline & Masc. & 25 & \multirow{2}{*}{50} & 70 & \multirow{2}{*}{140} \\
\hline
\end{tabular}




\begin{tabular}{|c|c|c|c|c|c|}
\hline \multirow{2}{*}{ Ago. } & Masc. & 49 & \multirow{2}{*}{105} & 73 & \multirow{2}{*}{146} \\
\hline & Fem. & 56 & & 73 & \\
\hline \multirow{2}{*}{ Set. } & Masc. & 47 & \multirow{2}{*}{110} & 70 & \multirow{2}{*}{142} \\
\hline & Fem. & 63 & & 72 & \\
\hline \multirow{2}{*}{ Out. } & Masc. & $x$ & \multirow{2}{*}{$x$} & 69 & \multirow{2}{*}{140} \\
\hline & Fem. & $x$ & & 71 & \\
\hline \multirow{2}{*}{ Nov. } & Masc. & $x$ & \multirow{2}{*}{$x$} & 69 & \multirow{2}{*}{140} \\
\hline & Fem. & $x$ & & 71 & \\
\hline \multirow{2}{*}{ Dez. } & Masc. & $x$ & \multirow{2}{*}{$x$} & 69 & \multirow{2}{*}{140} \\
\hline & Fem. & $x$ & & 71 & \\
\hline
\end{tabular}

Fonte: ARQUIVO PÚBLICO DO ESTADO DO RIO DE JANEIRO. Fundo Departamento de Educação. Cod. 0813 , Caixa 0077.

Como pode ser percebido na tabela 9 , o número de profissionais responsáveis pelo atendimento das crianças aumentou a partir do mês de agosto de 1948 e deste ponto por diante oscilou entre 7 e 8 profissionais (Tabela 9), o que podemos entender como uma forma de acompanhamento das demandas por matrículas. Em agosto de 1948, mês em que percebemos um salto de número de trabalhadoras, houve também um acrescimento na quantidade de crianças matriculadas, que passou de 50 para 105 (Tabela 8).

Pelos dados informados nos mapas de frequência de adjuntos, percebe-se que as categorias "guardiã" e "servente" foram suprimidas. O número referente a inspetoras de alunos passou de 1 para 2, a partir de agosto de 1948, e se manteve pelos meses seguintes. Embora não tenha sido localizada a documentação dos anos seguintes, sabe-se que a instituição foi mantida, pois em 1955, tanto o jardim de infância como o grupo escolar foram anexadas ao Instituto de Educação de Campos inaugurado neste ano (Martínez, Boynard, 2004). ${ }^{11}$

Tabela 8: Quantidade e categoria de profissionais do Jardim de Infância anexo ao Grupo Escolar Saldanha da Gama

\begin{tabular}{|c|c|c|c|c|c|c|c|c|c|c|c|}
\hline \multicolumn{12}{|c|}{ Jardim de Infância anexo ao Grupo Escolar Saldanha da Gama } \\
\hline & $\begin{array}{l}\text { Categoria } \\
\text { Profissional }\end{array}$ & Mar & Abr & Mai & Jun & Jul & Ago & Set & Out & Nov & Dez \\
\hline \multirow{6}{*}{$\begin{array}{l}1 \\
9 \\
4 \\
8\end{array}$} & Prof. efetiva & $\mathrm{x}$ & 1 & $x$ & $x$ & $\mathrm{x}$ & 1 & 1 & $x$ & $x$ & $x$ \\
\hline & Prof.substituta & $x$ & $\mathrm{x}$ & 1 & 1 & 1 & $x$ & 1 & $\mathrm{x}$ & $\mathrm{x}$ & $\mathrm{x}$ \\
\hline & Extranum $^{12}$. & $\mathrm{x}$ & $x$ & $\mathrm{x}$ & $\mathrm{x}$ & 1 & 4 & 3 & $\mathrm{x}$ & $\mathrm{x}$ & $\mathrm{x}$ \\
\hline & $\begin{array}{l}\text { Insp. de } \\
\text { alunos }\end{array}$ & 1 & 1 & 1 & 1 & 1 & 2 & 2 & $x$ & $x$ & $x$ \\
\hline & Servente & & & & & & 1 & 1 & $x$ & $x$ & $x$ \\
\hline & Total & 1 & 2 & 2 & 2 & 3 & 8 & 8 & $\mathbf{x}$ & $\mathbf{x}$ & $\mathbf{x}$ \\
\hline \multirow{2}{*}{$\begin{array}{l}1 \\
9\end{array}$} & Prof. efetiva & & 1 & 1 & 1 & 2 & 2 & 1 & 1 & 1 & 1 \\
\hline & Prof. substituta & $\mathrm{x}$ & 3 & 1 & 1 & 1 & 1 & 1 & 1 & 1 & 1 \\
\hline
\end{tabular}




\begin{tabular}{|c|c|c|c|c|c|c|c|c|c|c|c|}
\hline $\mathbf{4}$ & Extranum. & $\mathrm{x}$ & 3 & 3 & 3 & 3 & 2 & 3 & 3 & 3 & 3 \\
\hline $\mathbf{9}$ & $\begin{array}{c}\text { Insp. de } \\
\text { alunos }\end{array}$ & $\mathrm{x}$ & 2 & 2 & 2 & 2 & 2 & 2 & 2 & 2 & 2 \\
\hline & Total & $\mathbf{x}$ & $\mathbf{8}$ & $\mathbf{7}$ & $\mathbf{7}$ & $\mathbf{8}$ & $\mathbf{7}$ & $\mathbf{7}$ & $\mathbf{7}$ & $\mathbf{7}$ & $\mathbf{7}$ \\
\hline
\end{tabular}

Fonte: ARQUIVO PÚBLICO DO ESTADO DO RIO DE JANEIRO. Fundo Departamento de Educação. Cod. 0813, Caixa 0077.

A cidade de Campos é cortada pelo rio Paraíba do Sul. Na outra margem está situado o bairro Guarus que não experimentou os empreendimentos desenvolvimentistas e urbanistas que a região central vivenciou em inícios do século XX, onde foi instalado o único jardim de infância do outro lado do rio.

O Jardim de Infância Benta Pereira, em comparação com os demais jardins de infância apresentava uma pequena estrutura que acompanhava o baixo número de matrículas e de profissionais (Tabela 9). A documentação localizada e manuseada contempla os anos de 1948 e 1949 e não conseguimos localizar informação se a instituição foi criada anterior a essa data e se seguiu em funcionamento nos anos seguintes.

Tabela 9: Número de matrículas do Jardim de Infância Benta Pereira

\begin{tabular}{|c|c|c|c|c|c|}
\hline \multicolumn{6}{|c|}{ Jardim de Infância Benta Pereira } \\
\hline \multirow[b]{2}{*}{ Mês } & \multirow[b]{2}{*}{ Sexo } & \multicolumn{2}{|c|}{1948} & \multicolumn{2}{|c|}{1949} \\
\hline & & Mat. & Total & Mat. & Total \\
\hline \multirow{2}{*}{ Mar. } & Masc. & $x$ & \multirow{2}{*}{$x$} & 13 & \multirow{2}{*}{29} \\
\hline & Fem. & $x$ & & 16 & \\
\hline \multirow{2}{*}{ Abr. } & Masc. & 8 & \multirow{2}{*}{25} & 13 & \multirow{2}{*}{29} \\
\hline & Fem. & 17 & & 16 & \\
\hline \multirow{2}{*}{ Mai. } & Masc. & 8 & \multirow{2}{*}{25} & 13 & \multirow{2}{*}{29} \\
\hline & Fem. & 17 & & 16 & \\
\hline \multirow{2}{*}{ Jun. } & Masc. & 8 & \multirow{2}{*}{25} & 9 & \multirow{2}{*}{29} \\
\hline & Fem. & 17 & & 16 & \\
\hline \multirow{2}{*}{ Jul. } & Masc. & 10 & \multirow{2}{*}{28} & 12 & \multirow{2}{*}{34} \\
\hline & Fem. & 18 & & 22 & \\
\hline \multirow{2}{*}{ Ago. } & Masc. & 10 & \multirow{2}{*}{28} & 6 & \multirow{2}{*}{28} \\
\hline & Fem. & 18 & & 22 & \\
\hline \multirow{2}{*}{ Set. } & Masc. & 10 & \multirow{2}{*}{28} & 6 & \multirow{2}{*}{28} \\
\hline & Fem. & 18 & & 22 & \\
\hline \multirow{2}{*}{ Out. } & Masc. & 10 & \multirow{2}{*}{28} & 6 & \multirow{2}{*}{28} \\
\hline & Fem. & 18 & & 22 & \\
\hline \multirow{2}{*}{ Nov. } & Masc. & 10 & \multirow{2}{*}{28} & 6 & \multirow{2}{*}{28} \\
\hline & Fem. & 18 & & 22 & \\
\hline
\end{tabular}

Fonte: ARQUIVO PÚBLICO DO ESTADO DO RIO DE JANEIRO. Fundo Departamento de Educação. Cod. 0811 , Caixa 0076. 
Ali havia apenas uma professora responsável pelo grupo de alunos, Maria Conceição Diniz; e quem assinava os mapas de frequência escolar e de adjuntos era a diretora Afonsina Crisolina de Souza Rocha. Nas ausências de Maria Conceição assumiram outras profissionais, como Nair Peixoto da Silva (em 1948), Alzira Pereira da Rocha (em 1949) ou a própria diretora em alguns casos. Não havia guardiã, auxiliar de saúde, inspetor ou qualquer outro profissional na relação dos profissionais que atuavam na instituição, e é provável que o jardim de infância ocupasse a estrutura do Grupo Escolar homônimo, como previsto pela legislação educativa em vigor no período ${ }^{13}$.

Apesar de não ser objeto deste trabalho a análise sob o prisma do gênero, chama a atenção a preponderância de matrículas femininas neste jardim de infância. Não que esta situação não aparecesse em outros, principalmente no Jardim de Infância da Praça Nilo Peçanha, mas nesta instituição se manifestou de forma mais acentuada.

\section{Considerações finais}

Investir na produção de um panorama sobre os jardins de infância públicos estaduais campistas é um movimento importante para a identificação de aspectos referentes ao processo de escolarização da população infantil fluminense, bem como da configuração e comportamento do magistério público na estrutura educativa pré-escolar na primeira metade do século XX. Embora a documentação manuseada consista em um conjunto documental incompleto, com ausência de dados sobre meses e anos sequenciais, encará-la como dados e indícios oportunizou a reflexão sobre demandas e tensões existentes na implementação da pré-escola pública estadual a partir da década de 1920.

Pelos dados apresentados é possível vislumbrar a estrutura dos jardins de infância a partir da existência de um considerado número de profissionais especializados que atuavam nas instituições como guardiãs, inspetores, serventes, auxiliares de saúde, além de um amplo espectro da categoria docente formada por professoras efetivas, substitutas, adjuntas, extranumerária, estagiárias. As terminologias empreendidas para denominar cada tipo de professora, frente à estrutura burocrática pública estadual, indicam um alto nível de complexidade e especialidades que se assentava em distintas formas de contratação, tempo de serviço, experiência profissional e salários, que o magistério público fluminense alcançou com as reformas educativas empreendidas no decorrer da primeira metade do século $X X$. A compilação dos dados torna público e é um convite aos pesquisadores a investir em outras análises da temática, em razão da sua complexidade e de outras possíveis leituras e interpretações da documentação manuseada neste artigo.

Pelo manuseio dos mapas de frequência escolar e dos mapas de frequência de adjuntos tornou-se possível considerar que o conjunto documental, originalmente voltado para a produção de estatística e de cunho administrativo, extrapola o caráter quantitativo dos dados. Na coluna "observações", por exemplo, os registros sobre os eventos de ordem natural e social irrompem no tempo e no espaço escolar e contribuem para a compreensão da constituição da cultura escolar (Julia, 2001; Faria Filho et al, 2004). Ainda, pelos registros sobre as professoras, as informações nos permitem identificar a circulação delas entre instituições semelhantes, aspectos de formação e categorização dos profissionais da educação, entre outros aspectos.

History of Education in Latin America - HistELA, v. 3, e23477, 2020, p. 17 de 21 
Por fim, diante do volume de dados apresentados, outras indagações podem serem realizadas e aprofundadas, por exemplo, análise do currículo praticado pela Escola Normal de Campos referentes à formação das professoras para a atuação na pré-escola; o mapeamento das trajetórias profissionais das professoras que atuaram nos jardins de infância; o investimento comparativo entre as instituições a partir de dados demográficos, recuperação de acervo documental dos jardins de infância; levantamento de outras fontes historiográficas que deem conta da temática, entre outras. Tal fato demonstra a imprescindível necessidade de investimento em pesquisas sobre o estabelecimento da educação infantil via oferta pública na escala regional na primeira metade do século XX.

\section{Referências}

\section{Fontes}

A Noite. Rio de Janeiro: tipografia própria, ano 1936. (Hemeroteca Digital da Fundação Biblioteca Nacional).

Arquivo Público do Estado do Rio de Janeiro. Fundo Departamento de Educação, códigos 00809 a 00814, caixas 0076 e 0077.

Correio da Manhã, Rio de Janeiro: tipografia própria, ano 1936. (Hemeroteca Digital da Fundação Biblioteca Nacional).

Diário de Notícias, Rio de Janeiro: tipografia própria, ano 1943. (Hemeroteca Digital da Fundação Biblioteca Nacional).

Estado do Rio de Janeiro. Regulamento da Instrução Pública Primária do Estado do Rio de Janeiro. Decreto n. 2.105, de 2 de março de 1925.

Estado do Rio de Janeiro. Dispõe sobre as organizações pré-escolares, isto é, casas maternais e jardins de infância, e regula a admissão e as atribuições do respectivo pessoal, que constituirá um quadro a parte. Decreto n. 2.930, de 5 de julho de 1933.

O Fluminense, Niterói: tipografia própria, ano 1955. (Hemeroteca Digital da Fundação Biblioteca Nacional).

\section{Bibliografia}

Bertucci, L. M., Faria Filho, L. M. \& Oliveira, M. A. T. (2010). Edward P. Thompson: história e formação. Belo Horizonte: UFMG.

Boynard, M. A. A. P. (2006). A escola modelo anexa à Escola Normal de Campos: a experiência da "Seis de Março". Dissertação de mestrado. Universidade Federal Fluminense, Rio de Janeiro, RJ.

Dias, A. (2013). Os mapas de frequência escolar e a produção dos serviços de fiscalização do ensino no Estado do Rio de Janeiro (1924 - 1949). Roteiro, Joaçaba. Ed. Especial,13-40.

Dias, A. (2014). Entre laranjas e letras: processos de escolarização no distrito-sede de Nova Iguaçu (1916-1950). Rio de Janeiro: Editora Quartet. 
Faria Filho, L. M. de et al. (2004). A cultura escolar como categoria de análise e como campo de investigação na história da educação brasileira. Educação e Pesquisa. 30 (1), 139-159.

Faria Filho, L. M., Neves, L. S., \& Caldeira, S. M. (2005). A estatística educacional e a instrução pública no Brasil: Aproximações. S. M. Caldeias (Ed.). Modernidade, educação e estatísticas na lbero-américa dos séculos XIX e XX. (pp. 219-238). Lisboa: Educa.

Fernandes, R. A. N. (2009). Historiografia e identidade fluminense: a escrita da história e os usos do passado no estado do Rio de Janeiro entre as décadas de 1930 e 1950. Tese de doutorado. Pontifícia Universidade Católica do Rio de Janeiro, Rio de Janeiro, RJ, Brasil.

Gondra, J. G., \& Schueler, A. (2008). Educação, Poder e sociedade no império brasileiro. São Paulo: Cortez.

Gouvêa, M. C. S. de. (2006). Estatística social como técnica de governo: representações sobre os registros da população escolar (Portugal: 1880-1900). Em Congresso Brasileiro de História da Educação. Goiânia. Recuperado em 16/01/2019, de http://www.sbhe.org.br/novo/congressos/cbhe4/individuaiscoautorais/eixo03/Maria\%20Cristina\%20Soares\%20de\%20Gouvea\%20-

\%20Texto.pdf.

Julia, D. (2001) A cultura escolar como objeto historiográfico. Revista Brasileira de História da Educação, 1, 9-44.

Martínez, S. A. \& Boynard, M. A. A. P. (2004). Memórias de 1955: O (re)nascer do Instituto de Educação de Campos. Em M. Gantos (Ed.). Campos em perspectiva. (pp. 13-51). Rio de Janeiro: Papel Virtual.

Martínez, S. A. (2009). Formando os professores "no interior": a criação da Escola Normal de Campos no processo de implementação do sistema de instrução pública e de profissionalização do magistério no Estado do Rio de Janeiro. Anuario Historia de la educación. Buenos Aires, 10, s/p.

Martínez, S. A. (2012) A escola normal de Campos na gênese do processo de formação e profissionalização do magistério no norte fluminense. Em S. C. Lopes; M. W. Chaves (Ed.). A história da educação em debate: estudos comparados, profissão docente, infância, família e Igreja (pp. 123-140) Rio de Janeiro: Mauad X, FAPERJ.

Mignot, A. C. V. (2007). Entre cartas e cartões postais: uma inspiradora travessia. Em A. C. V. Mignot, \& J. G. Gondra (Ed.). Viagens Pedagógicas. (pp. 246-276). São Paulo: Ed. Cortez.

Mignot, A. C. V., \& Martínez, S. A. (2002). Antonia Ribeiro de Castro Lopes. Em M. de L. Favero, \& J. M. de Britto. (Ed.). Dicionário de Educadores do Brasil. (2ª ed.) (pp. 89-96) Rio de Janeiro: Editora UFRJ / Mec-Inep-Comped.

Nagle, J. (1974). Educação e sociedade na Primeira República. São Paulo: EPU.

Paulilo, A. L. (2009). As estratégias de administração das políticas públicas de educação na cidade do Rio de Janeiro entre 1922 e 1935. Revista Brasileira de Educação, 14 (42), 440 - 455.

Paulilo, A. L. (2017). Administração educacional na sede do governo Republicano entre 1922 e 1935. Revista Educação Pública, 26 (61), 159-175. 
Rosselini, R. (2019). Formando os cidadãos fluminenses: a escola primária no estado do Rio de Janeiro durante a primeira república. Campos dos Goytacazes: Essentia Editora IFFluminense.

Schueler, A. F. M. de. "Grandeza da Pátria e Riqueza do Estado": expansão da escola primária no Estado do Rio de Janeiro (1893-1930). Revista Educação Pública Cuiabá, v. 19, n. 41, p. 535-550, set./dez. 2010.

Schueler, A. F. M. de., \& Magaldi, A. M. B. de M. Educação escolar na Primeira República: memória, história e perspectivas de pesquisa. Tempo, v. 13, n. 26, 2009, p. 32-55.

Thompson, E. P. (2011). Costumes em comum: estudos sobre a cultura popular tradicional. São Paulo: Ed. Companhia das Letras.

Vidal, D. G. (2007). O fracasso das reformas educacionais: um diagnóstico sob suspeita (Rio de Janeiro, 1927-1930). Educação em Foco, n. especial, 11-24.

Villela, H. de O. S (2002). Da Palmatória à Lanterna Mágica: A Escola Normal da Província do Rio de Janeiro entre o artesanato e a formação profissional - (18681876). Tese de doutorado. Universidade de São Paulo. São Paulo, SP, Brasil.

\title{
Notas
}

\begin{abstract}
${ }^{1}$ A pesquisa contou com recursos provenientes do edital PROPPG № 02/2018, da Universidade Estadual do Norte Fluminense.

${ }^{2}$ Revista Contemporânea de Educação, v. 14, n. 30, mai./ago., 2019.

${ }^{3}$ Os mapas de frequência escolar consultados no Fundo de Educação, código: 00809 a 00814; caixas 0076 e 00770.

${ }^{4}$ Sobre as reformas da instrução pública na primeira metade do século XX, Vidal (2007) e Paulilo $(2009,2017)$ nos fornecem elementos para pensarmos o estado do Rio de Janeiro.

${ }^{5}$ Antonia Lopes era catedrática da Escola Normal de Campos, foi uma destacada professora no contexto campista e quiçá nacional. Mantinha contato com Édouard Cleparède (1873-1940), e foi aluna do Instituto Jean Jacques Rousseau, em Genebra. Ao retornar ao Brasil fundou do Instituto Cleparède, instituição estabelecida pela perspectiva da Educação Nova onde a criança era o centro do processo de ensino-aprendizagem. Ver: Mignot, Martínez (2002); Boynard (2006); Mignot (2007). ${ }^{6}$ Utilizam-se os termos classe e período na organização e distribuição dos alunos de acordo com a idade, como prática da escola seriada.
\end{abstract}

${ }^{7}$ Atuou como professora na Escola Complementar/Grupo Escolar Quinze de Novembro (Rosselini, 2019).

${ }^{8}$ Somente a partir de maio de 1933 que passa a figurar o mapa de frequência de adjuntos, o que pode ser entendido como uma especialização do serviço de fiscalização da instrução pública estadual, como forma de controle da frequência do corpo profissional da instituição.

${ }^{9}$ A Escola ao Ar Livre Presidente Wencesláo Bráz foi criada em 1919. Seu programa de ensino era de "escola primária elementar, seguindo o programa dividido em quatro séries, vigente nas escolas isoladas do perímetro urbano". Rosselini (2019) associa a criação da Escola ao Ar Livre Presidente Wencesláo Bráz, criada em Campos, às viagens realizadas por Nilo Peçanha à Europa em 1911.

${ }^{10}$ Foi professora da Escola Maternal Mariana Barreto (Correio da Manhã, 25/5/1934, p. 6, n. 12114). Consta como aluna do curso de Pedagogia da Faculdade Nacional de Filosofia, que foi criado em pelo Decreto-Lei o․ 1.190 de 4 de abril de 1939 (Diário de Notícias, 1/7/1943, p. 6, n. 6344; $17 / 11 / 1943$, p. 6 , n. $6462 ; 21 / 11 / 1943$, p. 6 , n. 6466 ; 24/11/1943, p. 6 , n. $6468 ; 25 / 11 / 1943$, p. 6 , n. 6469; 9/12/1943, p. 6, n. 6481; 14/12/1943, p. 8, n. 6794). No Jornal "O Fluminense", de 22 de maio de 1955, publicou que "A professora Maria Geny Ferreira da Silva declinou do convite que lhe foi endereçado para o alto ponto de Diretor do Instituto de Educação de Niterói. Trata-se de uma das mais competentes figuras do ensino fluminense que vem emprestando proveitosamente suas atividades na Inspetoria de Petrópolis. A referida educadora, que se tem destacado nos diversos setores educacionais, salientando-se em recente concurso no Distrito Federal para o ensino supletivo, em que tirou o primeiro ligar, entre centenas de candidatos, justificou sua recusa por preferir os trabalhos na inspeção escolar no Estado do Rio. Será, portanto, nomeado um novo diretor para aquele estabelecimento" (O FLUMINENSE, 22/5/1955, n. 22278, p. 1). O Laboratório de História 
Oral e Imagem da Universidade Federal Fluminense (LABHOI/UFF) realizou entrevista com a personagem e a gravação está disponível para consulta mediante agendamento.

11 Para Martínez e Boynard (2004), a criação do Instituto de Educação está situada no contexto de mudanças que estavam ocorrendo no sistema de educação, em nível nacional, pelo Decreto-Lei no 8.530 de 2 de janeiro de 1946, que reestruturou os cursos de formação de professores. No estado do Rio de Janeiro a reestruturação se deu pela Lei n. 2.146, de 12 de maio de 1954, que criou os Institutos de Educação das cidades de Niterói e Campos a partir da estrutura educativa e alunado das Escolas Normais das duas cidades.

12 Extranumerária.

${ }^{13}$ Foram localizadas referências ao Grupo Escolar Benta Pereira no jornal "Correio da Manhã" em 24 e 27 de abril de 1929. 